\title{
A new Robertsonian fusion in the multiple chromosome polymorphism of a mediterranean population of Gobius paganellus (Gobiidae, Perciformes)
}

\author{
Vicente Giles, \\ Guillermo Thode and \\ M. Carmen Alvarez
}

\author{
Departamento de Genética, Facultad de Ciencias, \\ Universidad de Málaga, Malaga, Spain.
}

\begin{abstract}
Karyotypic analysis of 67 individuals of a Mediterranean population of $G$. paganellus has revealed three new karyomorphs: $D_{2} F_{1}^{\prime},(2 n=45, N F=46), F_{2} F_{1}^{\prime},(2 n=45, N F=48), D_{1} F_{1} F_{1}^{\prime},(2 n=45, N F=47)$, in addition to the seven previously reported by Thode et al. (1985). The $C$-banding pattern and the meiotic configurations clearly show that the mechanism involved is a new centromeric fusion. The high level of intra-individual variability for this rearrangement suggests a possible origin within this population. The involvements of this fusion in the polymorphism of $G$. paganellus are discussed mainly in comparison with another centromeric fusion.
\end{abstract}

\section{INTRODUCTION}

Although the majority of chromosome polymorphisms detected in fish have taken the form of Robertsonian translocations (Beçak et al., 1966; Uyeno and Smith, 1972; Vasiliev, 1978, 1980; Ojima and Kashiwagi, 1981; Viktorovsky and Ermolensko, 1982 and Foresti et al., 1984), they have been reported mainly in several species of Salmonids, especially in the genus Salmo (Hartley and Horne, 1984). Ohno $(1970,1974)$ has suggested that centric fusions in such species are the reflection of a diploidisation process from a tetraploid ancestral karyotype.

In a preliminary investigation of chromosome polymorphisms in a Mediterranean population of the Perciform G. paganellus, Thode et al. (1985) described seven different karyomorphs. Six of them are derived from a deletion and a centric fusion, both of which appear in a combined or in an independent form. In addition, one individual showed a karyotype which presumably originated from a pericentric inversion. A very low level of intra-individual variability involving centromeric association and not concerned with any of the above rearrangements was also found in that sample (Alvarez and Thode, in press). This association seems to have given rise to a new centromeric fusion in the same population as shown by the appearance of three new karyomorphs in a deeper study carried out in a larger sample from the same population. We show in this paper a new aspect of the multiple chromosome variability in $G$. paganellus by means of the analysis of this new rearrangement in relation to the rest of the chromosome changes, especially the fusion $F$ also involved in the polymorphism of this species.

\section{MATERIAL AND METHODS}

Sixty-seven specimens of both sexes of $G$. paganellus from a single population were captured along $60 \mathrm{~km}$ of the Spanish South Mediterranean coast during the period 1982-84.

Mitotic and meiotic metaphases were obtained from cells of kidney and testis according to the technique of Capanna et al (1972) suitably modified by Alvarez et al. (1980). Chromosomes were classified on the basis of the arm-ratio values proposed by Levan et al. (1964). For identification of the NORs, slides older than 7 days were silver 
256

V. GILES, G. THOLE AND M. CARMEN ALVAREZ

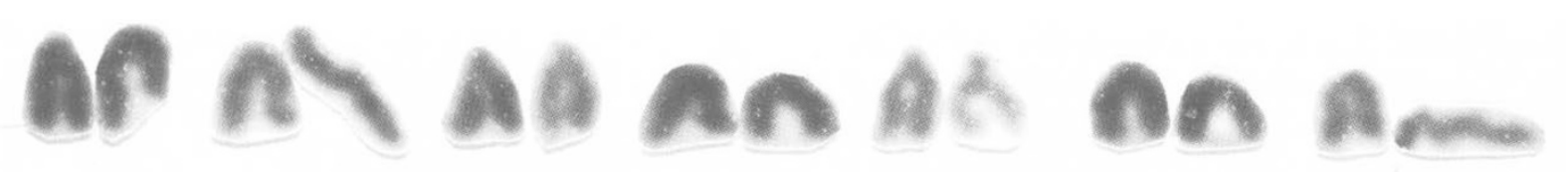
AA $\rightarrow$ DA $A$ AB on on an ba MA ne an to D $_{2} F_{1}^{\prime}$ ด ล $\triangle A X_{+}$

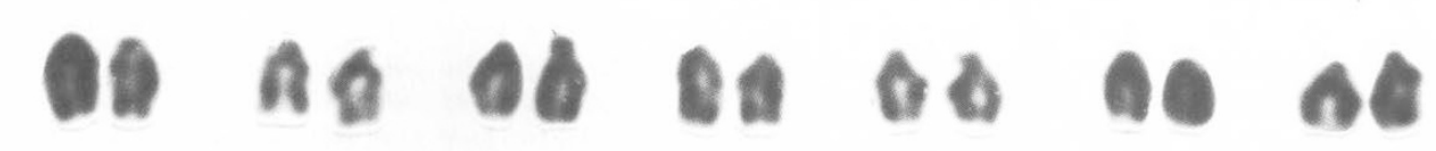
On no an on an an as

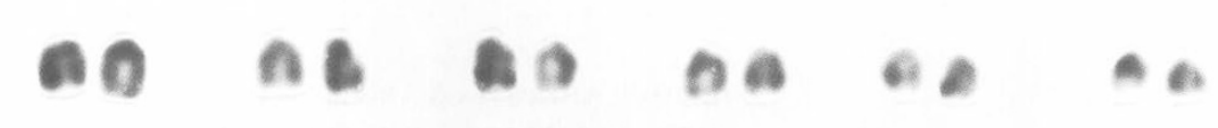
$D_{1}, F_{1}^{\prime}$ $.1 .98+$ an an an an on an on an on an an an al an an an an on ad ar $\mathbf{F}_{2} \mathbf{F}_{1}^{\prime}$ 5 pm XX คค Figure 1 Karyotypes from three new morphs in $G$. paganellus (from top to bottom): $D_{2} F_{1}^{\prime}(2 n-45, N F-46), D_{1} F_{1} F_{1}^{\prime}(2 n=45$,
$N F=47), F_{2} F_{1}^{\prime}(2 n=45, N F=48)$. The chroriosome pairs supposedly implied in the polymorphism are placed separately. 
stained following the method of Rufas et al. (1982). The C-banding technique according to Sumner (1972) was applied to each different karyomorph.

\section{RESULTS}

The analysis of somatic metaphases has revealed that 5 of the 67 individuals have one of three new karyomorphs in addition to which they all have in common a large biarmed chromosome of about $4.66 \mu \mathrm{m}$ in length (fig. 1, arrowheads). The nomenclature adopted is based on that followed in describing the first seven karyomorphs (Thode et al., 1985; table 1), which takes into account the

Table 1 Karyological data of 67 specimens of $G$. paganellus showing 10 karyomorphs

\begin{tabular}{|c|c|c|c|c|c|c|}
\hline \multirow[b]{2}{*}{ Morphs } & \multirow[b]{2}{*}{$\begin{array}{l}\text { No. individuals } \\
\delta \sigma \text { and } q Q\end{array}$} & & \multicolumn{4}{|c|}{ Karyotype characteristics } \\
\hline & & \multirow{2}{*}{\multicolumn{2}{|c|}{$2 n$}} & \multicolumn{2}{|c|}{ Morphology } & \multirow[t]{2}{*}{$N F$} \\
\hline & & & & $M-S m$ & $S t-A$ & \\
\hline${ }^{*} \mathrm{D}_{2}$ & 10 & 46 & & & 46 & 46 \\
\hline$* D_{1}$ & 9 & 47 & & & 47 & 47 \\
\hline${ }^{*} B$ & 9 & 48 & & & 48 & 48 \\
\hline${ }^{*} F_{1}$ & 10 & 47 & 1 & 1 & 46 & 48 \\
\hline$* F_{2}$ & 8 & 46 & 2 & 2 & 44 & 48 \\
\hline${ }^{*} D_{1} F_{1}$ & 15 & 46 & 1 & 1 & 45 & 47 \\
\hline$* I_{1}$ & 1 & 48 & 1 & 1 & 47 & 49 \\
\hline$D_{2} F_{1}^{\prime}$ & 3 & 45 & 1 & 1 & 44 & 46 \\
\hline$F_{2} F_{1}^{\prime}$ & 1 & 45 & 3 & 3 & 42 & 48 \\
\hline$D_{1} F_{1} F_{1}^{\prime}$ & 1 & 45 & 2 & 2 & 43 & 47 \\
\hline
\end{tabular}

* Thode et al. 1.985 . type of chromosome changes apparently involved in this polymorphism. The $D_{2} F_{1}^{\prime}(2 n=45, N F=$ $46)$ consists of one metacentric and 44 subtelocentrics-acrocentrics. The $F_{2} F_{1}^{\prime}(2 n=45, N F=48)$ comprises one big metacentric, one pair of smaller metacentrics and 42 subtelocentrics-acrocentrics. The $D_{1} F_{1} F_{1}^{\prime}(2 n=45, N F=47)$ includes 1 big metacentric, 1 smaller metacentric and 43 monoarmed chromosomes (fig. 1; table 1).

From a detailed meiotic observation of the $D_{2} F_{1}^{\prime}$ and the $D_{1} F_{1} F_{1}^{\prime}$ morphs, we identified 21 bivalents plus a rod-shaped trivalent $(t)$ in the former (fig. 2, left) and 20 normal bivalents, one rod-shaped trivalent $(t)$ and a heteromorphic bivalent $(h)$ in the latter (fig. 2, right).

An exhaustive analysis of each specimen revealed an intra-individual variability in 20 individuals ( 29.85 per cent), due to Robertsonian translocations always regarding the same two pairs engaged in the centromeric fusions $F$ and $F^{\prime}$. The incidence and the characteristics of this polymorphism are shown in table 2 .

Most metaphases showed silver depositions in pericentromeric locations on the smallest pair, while a few displayed secondary NORs at the same position on the second largest acrocentric pair (figs. 3 and 4). When the secondary NORs were expressed, four stained regions occasionally appeared. The range of observed interphase nucleoli confirmed the number of NORs estimated from the silver stained metaphases.

The C-banding technique proved to be useful for confirming the fusion mechanism for both $F$ and $F^{\prime}$ (fig. 3). It also enabled us to identify the

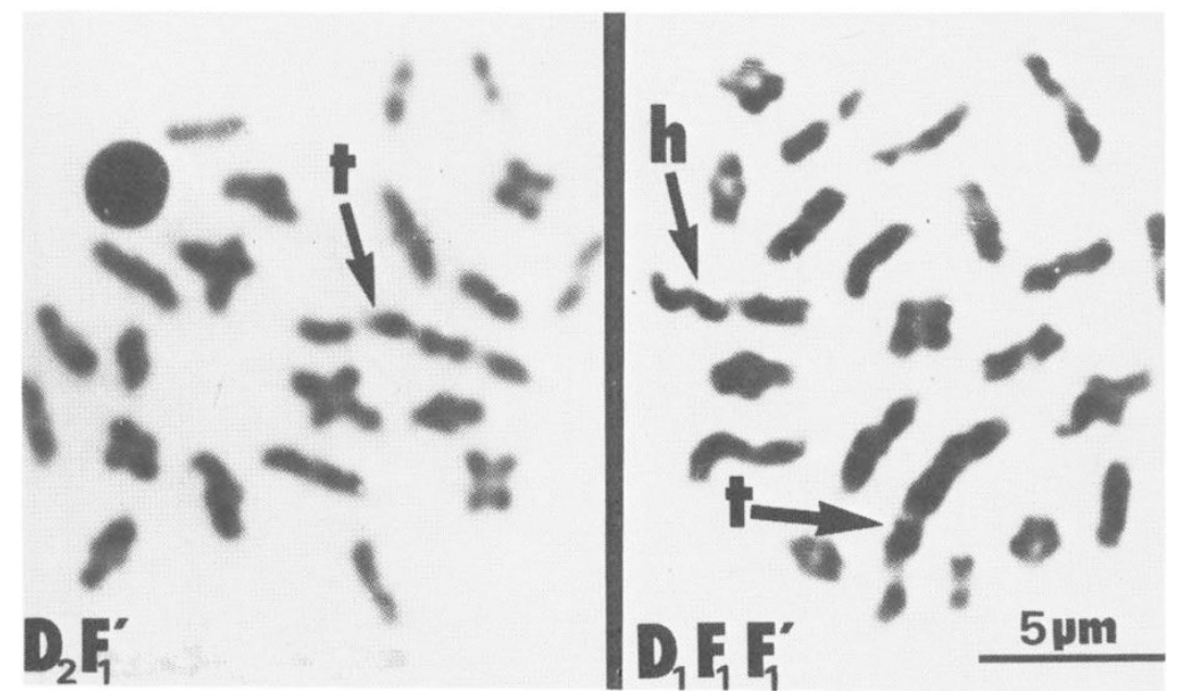

Figure 2 Meiotic metaphases $I$ in two morphs with fusion $F^{\prime}$ (see in the text the significance of the arrowheads). 
Table 2 Intraindividual polymorphism in 20 individuals of $G$. paganellus

Fish of

No. metaphases karyomorph $\%$ of cells with $\neq 2 n$

\begin{tabular}{rrll}
\hline 1 & 112 & $F_{1}$ & $10^{\prime} 7\left(F_{2}\right), 9^{\prime} 8(B)$ \\
4 & 63 & $F_{2}$ & $38\left(F_{2} F_{1}^{\prime}\right)$ \\
6 & 56 & $F_{2}$ & $1^{\prime} 2\left(F_{2} F_{1}^{\prime}\right)$ \\
9 & 161 & $D_{1}$ & $9^{\prime} 3\left(D_{1} F_{1}^{\prime}\right)$ \\
14 & 63 & $I_{1}$ & $1^{\prime} 6\left(I_{1} F_{1}^{\prime}\right)$ \\
17 & 38 & $F_{1}$ & $15^{\prime} 8\left(F_{1} F_{1}^{\prime}\right)$ \\
29 & 57 & $B$ & $1^{\prime} 8\left(F_{1}^{\prime}\right)$ \\
33 & 69 & $F_{1}$ & $6^{\prime} 8(B), 1^{\prime} 4\left(F_{2}\right)$ \\
35 & 181 & $D_{2} F_{1}^{\prime}$ & $5^{\prime} 8\left(D_{2}\right)$ \\
39 & 75 & $D_{2}$ & $2^{\prime} 7\left(D_{2} F_{1}^{\prime}\right)$ \\
42 & 61 & $D_{1} F_{1}$ & $1^{\prime} 6\left(D_{1} F_{1} F_{1}^{\prime}\right)$ \\
43 & 78 & $D_{1}$ & $2^{\prime} 6\left(D_{1} F_{1}\right)$ \\
48 & 45 & $D_{1} F_{1}$ & $2^{\prime} 2\left(D_{1}\right)$ \\
49 & 93 & $D_{2} F_{1}^{\prime}$ & $17^{\prime} 2\left(D_{2}\right)$ \\
51 & 50 & $D_{2}$ & $4\left(D_{2} F_{1}^{\prime}\right)$ \\
53 & 66 & $D_{1} F_{1}$ & $1^{\prime} 5\left(D_{1} F_{1} F_{1}^{\prime}\right)$ \\
54 & 44 & $D_{1} F_{1}$ & $2^{\prime} 3\left(D_{1}\right), 13^{\prime} 8\left(D_{1} F_{1} F_{1}^{\prime}\right)$ \\
58 & 38 & $D_{2} F_{1}^{\prime}$ & $2^{\prime} 6\left(D_{2}\right)$ \\
60 & 42 & $F_{1}$ & $10\left(F_{2}\right)$ \\
63 & 56 & $D_{2}$ & $11^{\prime} 2\left(D_{2} F_{1}^{\prime}\right)$ \\
\hline
\end{tabular}

long arm of the small metacentric chromosome as one of the mid-sized acrocentrics lacking the telomeric band (figs. 3 and 4). The rest of the chromosomes involved in the fusions were not recognised by this method because of their similar heterochromatic patterns (Thode and Alvarez, in press; fig. 4).

\section{DISCUSSION}

The addition of a new chromosome change to the previously reported multiple chromosome polymorphism in G. paganellus (Thode et al., 1985) is
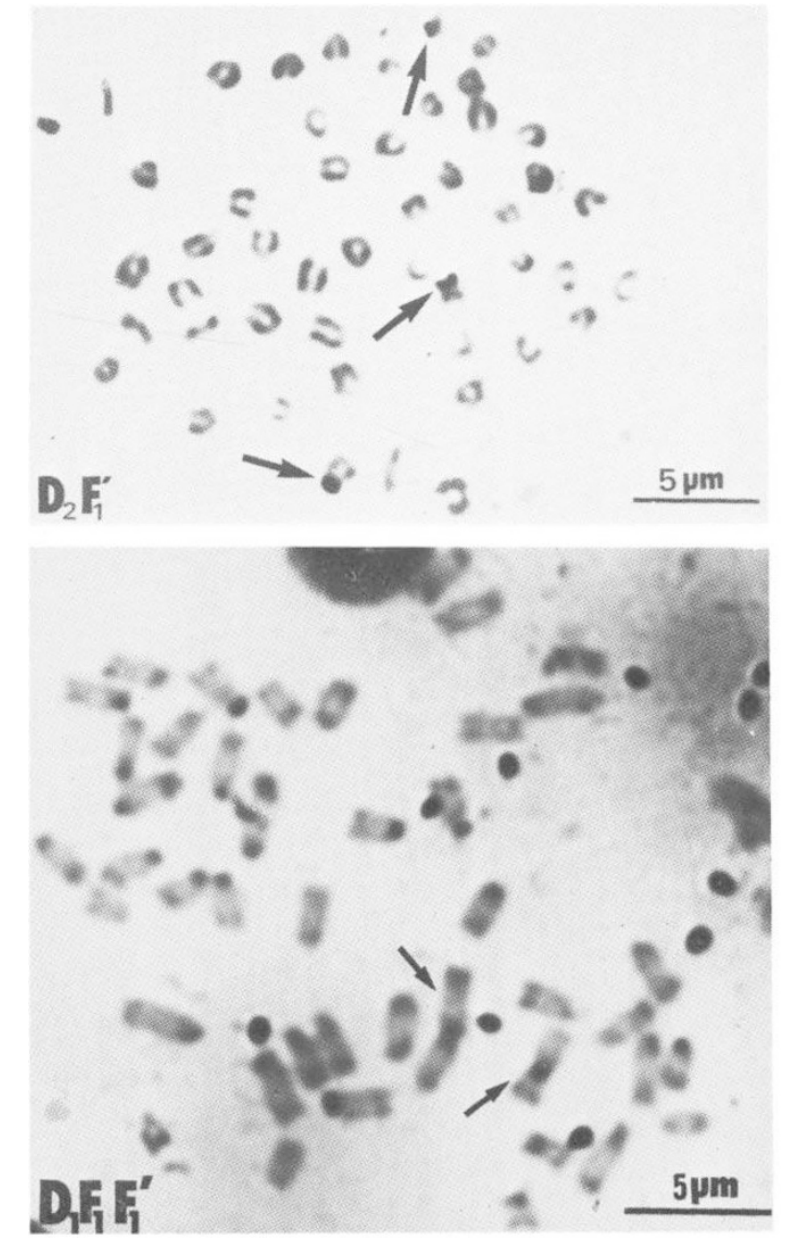

Figure 3 Top: Metaphase showing three Ag-stained NORs (arrowheads). Bottom: Partial C-banding metaphase displaying the two types of fused chromosomes $F^{\prime}$ and $F$ (arrowheads).

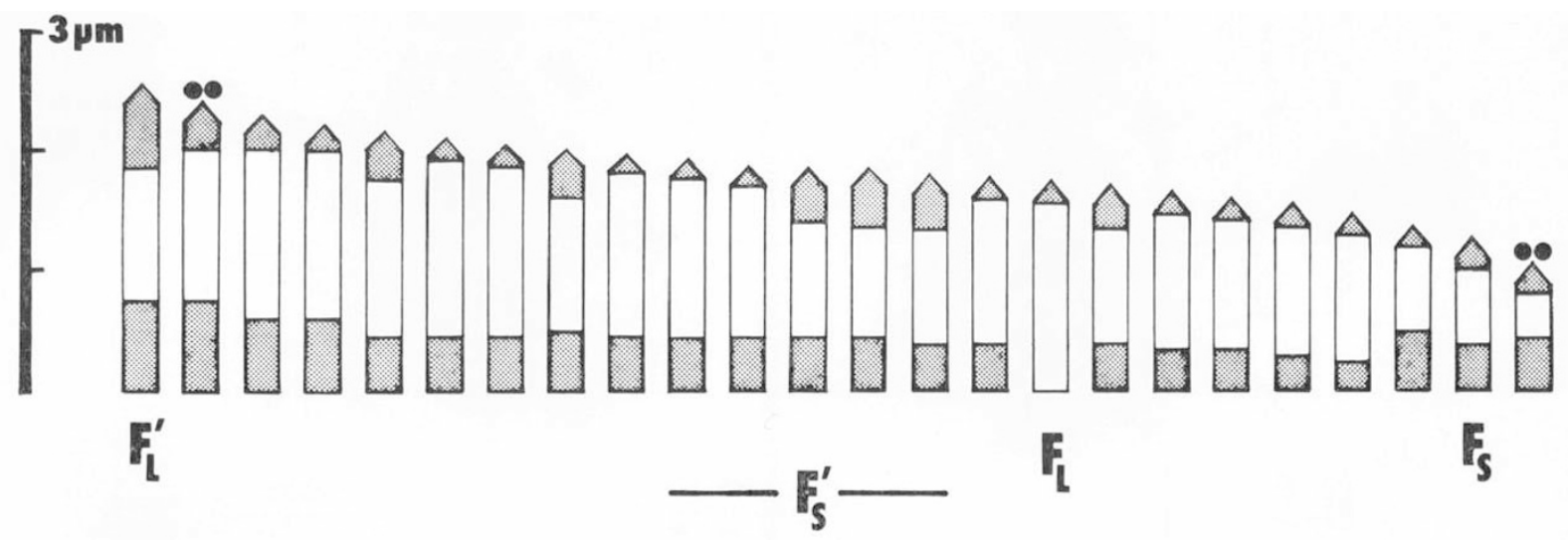

Figure 4 Standard idiogram of the basic karyotype of $G$. paganellus showing the Ag-NORs (dots), the C-banding pattern and the chromosomes presumably involved in both fusions (see in the text the meaning of the symbols). 
reflected in the karyomorphs $D_{2} F_{1}^{\prime}, F_{2} F_{1}^{\prime}$ and $D_{1} F_{1} F_{1}^{\prime}$, which display a new single metacentric (fig. 1) presumably formed by a centromeric fusion between two monoarmed chromosomes of the basic complement represented in the $B$ morphs (table 1). This can be deduced from its constitutive heterochromatin pattern (fig. 3). Based on measurements of chromosome lengths and using the NOR chromosomes as markers, the long arm of the new fused chromosome $\left(F_{L}^{\prime}\right.$, fig. 4$)$ has been identified as the largest chromosome of the basic complement, and the short one ( $F_{S}^{\prime}$, fig. 4$)$ as any of the mid-sized acrocentrics. Also in fig. 4 the chromosomes identified as those involved in fusion $F$ are indicated $\left(F_{L}\right.$ and $\left.F_{S}\right)$.

Meiotic metaphases of the $D_{2} F_{1}^{\prime}$ and $D_{1} F_{1} F_{1}^{\prime}$ morphs (fig. 2) allowed us to record their respective diploid numbers and to confirm the fusion mechanism through the identification of the trivalent $(t)$ composed of the fused and unfused homologues. The heteromorphic bivalent $(h)$ in the $D_{1} F_{1} F_{1}^{\prime}$ is the result of the already described fusion $F$ and deletion $D$ (Thode et al., 1985).

Inter-individual chromosome polymorphism involving centric fusions and dissociations seems to be able to persist in natural populations only under special preconditions (White, 1973). One of these is that the resulting metacentric element should be approximately equal armed. The two metacentrics $F$ and $F^{\prime}$ show arm ratios of 1.37 and 1.42 respectively. This difference could partly account for the differential success of these fusions in this population. Whereas fusion $F$ appears with a frequency of 0.33 and has reached fixation ( 9 homozygous, table 1 ), the $F^{\prime}$ has only been detected in the heterozygous state with a frequency of $0 \cdot 04$.

In any case, the persistence of these fusions can be supported by the common tendency in many groups of fish towards a reduction in the chromosome number by centric fusions which has been interpreted as an adaptative trait (Stebbins, 1958; Nikolsky, 1976) and which seems to be recurrent not only in this species but also in other members of the genus Gobius (unpublished data).

The different role of these fusions in the interindividual polymorphism is also reflected in their characteristic mode of expression at the intraindividual level (table 2 ). We can see from the data that intra-individual cellular variability due to $F$ always occurs in heterokaryotypes according to the following trends $\left(B \leftarrow F_{1} \rightarrow F_{2} ; D_{1} F_{1} \rightarrow D_{1}\right)$, except for specimen No. $43\left(D_{1}\right)$ where 2.6 per cent of the cells display the $D_{1} F_{1}$ karyomorph. However, the intra-individual variability due to $F^{\prime}$ appears in both the homo and heterokaryotypes for this fusion, keeping in mind that individuals with $F^{\prime}$ in the homozygous state are absent from this sample.

Two alternatives have been proposed by Beçak et al. (1966) to account for the origin of Robertsonian intraindividual polymorphism in fish: (1) "Dissociations and unifications" may take place early in embrionic life without apparent harm and (2) "The individuals heterozygous for Robertsonian translocations tend towards reconstitution of homokaryotypes". If the first assumption is correct intra-individual polymorphism should happen in any individual, and if the second one is correct, only fusion heterozygotes would show intercellular variability. In our case the second hypothesis seems to account for the origin of $F$ and the first one for $F^{\prime}$.

The origin of this variability is better understood if we analyse the distribution of the frequencies of both fusions, appearing either partially or totally in each individual (table 3(a), (b)). The $F$ distribution (table $3(\mathrm{a})$ ) is markedly monopolar and suggests that this fusion is in a highly stable state in 21 heterozygous and 9 homozygous invididuals although there is a slight instability, probably tending to the homozygous condition, in the five individuals with frequencies of $F$ between 79.5 per cent and 97.8 per cent. Individual $D_{1}$ with 2.6 per cent of $D_{1} F_{1}$ type metaphases could account for the recurrency of this rearrangement.

Table 3 Incidence of both fusions in the population

(a)

\begin{tabular}{lllllllll}
\hline $\begin{array}{l}\text { No. of individuals } \\
\% \text { metaphases with } F\end{array}$ & 1 & 1 & 1 & 1 & 1 & 1 & 21 \\
\end{tabular}

(b)

\begin{tabular}{lllllllllllll}
\hline $\begin{array}{l}\text { No. of invididuals } \\
\% \text { metaphases with }\end{array} F^{\prime}$ & 1 & 2 & 1 & 1 & 1 & 1 & 2 & 1 & 1 & 1 & 1 & 1 \\
\hline
\end{tabular}


$F^{\prime}$ shows a bipolar distribution (table $3(\mathrm{~b})$ ) with a gap between frequencies of 38 per cent and 82.8 per cent. Values over 82.8 per cent represent individuals where $F^{\prime}$ is established although there is slight remaining instability in three of them, giving rise to dissociation of the previously fused chromosomes in a few cells. Frequencies below 38 per cent might be interpreted as the occurrence of associations between $F_{L}^{\prime}$ and $F_{S}^{\prime}$ due to a preferential attraction of their heterochromatic regions (White, 1973).

The observation made three years ago (Alvarez and Thode, in press) that only 3 out of 26 individuals showed this same type of association in 12-15 per cent of their cells, and the subsequent increase of its frequency since then, might suggest that the already established $F^{\prime}$ is the result of repetitive associations of the chromosomes involved up to a threshold, probably situated somewhere in the "gap" (table 3(b)). This is probably necessary to guarantee both its stability and the chance of being integrated into the germ line.

In spite of the above suggestions raised from the available data bout the origin of $F^{\prime}$, we can not rule out the possibility that $F^{\prime}$ came from a neighbouring population which partially overlaps with the analysed one, bearing in mind the low frequency of $F^{\prime}$ detected so far and the lack of information about its distribution area. This, and other questions, prompt further extension of this study in space and time in order to evaluate the actual contribution of this mechanism to the karyotype diversity of $G$, paganellus.

\section{REFERENCES}

ALVAREZ, M. ( . ( AN(), J. AN1) IHODE, G. 1980. I)NA content and chromosome complement of Chromis chromis (Pommacentridae, Perciformes). Caryologia, 33, 267-274.

AIVARI:Z, M. ( AND THODE, (i. 1983. Variabilidad cromosómica en algunas especies del género Gobius (Perciformes, Teleósteos). Folia Vertebrata (in press).
BI:(AK, W., BECAK. M. I. ANI) (JINO, S. 1966. Intraindividual chromosamal polymorphism in the green sunfish (Lepomis (yanellus) as evidence of somatic segregation. Cytogenetics, $5,313-320$.

(APANNA, E., CATAUDFI.IA, S. ANI) VOLPE, R. 1972. Osservazioni morfologiche e cariologiche su di un ibrida Salmo trutta $\times$ Salvelinus fontinalis. Boll. Pesca Pisci Idrobiol., 27, $245-257$.

FORFSII, F, FORESTI I)I ALMEIUA TOIFDO, I. ANI) AI.MIII)A TOLEDO. $F$. S. 1984. Chromosome studies in Gymnotus carapo and Gymnotus sp (Pisces, Gymnotidae). Caryologia, $37(1-2), 141-146$

IIAR'ILEY, S. AND HORNF, M. 1984. Chromosome relationships in the genus Salmo. (hromosoma, 90, 229-237.

LEVAN, A., IRIDDCIA, K. AND SANDBERC; A. A. 1964. Nomenclature for centromeric position on chromosomes. Hereditas, 52, 201

Nikolsky, (i. 1976. The interrelation between variability of characters, effectiveness of energy utilization and karyotype structure in fishes. Evolution, 30, 180-185.

(O1IN(), s. 1970. The enormous diversity in genome sizes of fish as a reflection of nature's extensive experiments with gene duplication. Trans. Am. Fish. Soc, 99, 120-130.

()HNO, S. 1974. Animal Cytogenetics Vol. 4. Chordata I: Protochordata, Cyclostomata, and Pisces. Gebruder Borntraeger, $99 \mathrm{pp}$.

OJIMA, Y. ANI) KASHIWAGI. F. 1981. Chromosomal evolution associated with Robertsonian fusion in the genus Dascyllus (Chrominae, Pisces). Proc. Japan. Acad., 57B, 368.

STIBIIINS, (i. L. 1958. Longevity, habitat and release of genetic variability in the higher plants. Cold Spring Harbor Symp Quant. Biol, 23, 365-378.

SUMNER, A. T, 1972. A simple technique for demonstrating centromeric heterochromatin. Exp. Cell Res., 75, 304-306.

THODE, G. ANI) AI.VAREY, M. C. 1983. Implicaciones evolutivas y taxonómicas derivadas del estudio cariológico de 6 especies del género Gobius (Orden Perciformes). Folia Vertebrata (in press).

THODE, G.. (ill.s, V. AND ALVARE7, M. (. 1985. Multiple Chromosome Polymorphism in Gobius paganellus (Teleostei, Perciformes). Heredity, $54(3-7)$.

UYTNO, T. AND SMITH, G. R. 1972. Tetraploid origin of the karyotype of Catostomid fishes. Science, 175, 644-646.

VASILIH.V, V. P. 1978. Chromosome polymorphism in Spicara smaris (Pisces, Centracanthidae). Zool. Zn., 57, 1276-1279.

VASILITV, V. P. 1980. The selective mortality of different chromosome morphs in Spicara flexuosa. Raf. Genetica, $52-53,327-331$.

VIKTOROVSKY, R. M. AND ERMOI.I:NSKO, L. N. 1982. The chromosomal complexes of Coregonus nasus and Coregonus lavaretus, and the problem of Coregonus karyotype divergence. Citologia, 24(7), 797-801.

WHITT, M. J. 1). 1973. Animal Cytology and Evolution, 3rd ed. Cambridge University Press. 961 pp 